\title{
Keep 'Em Separated Desire Lines Analysis of Bidirectional Cycle Tracks in Montreal, Canada
}

\author{
Michael Seth Wexler and Ahmed El-Geneidy
}

\begin{abstract}
As cities worldwide try to increase the adoption of the bicycle as a legitimate mode of urban transportation, the perception of danger plays a significant role in deterring potential new users. In a study conducted in Montreal, Quebec, Canada, bicycle users claimed to perceive intersections with bidirectional cycle tracks twice as negatively as they perceived either similar protected facilities midblock or intersections with painted bicycle lanes. This study aimed to understand this negative perception through a fine-grained analysis and observation of the interplay between infrastructure design and bicycle users' behavior at these intersections. Researchers used the Desire Lines Analysis tool pioneered by Copenhagenize Design Company and developed recommendations and design interventions for two intersections with bidirectional facilities in the city of Montreal. Study results demonstrated that most users followed the prescribed routes of the street design through each intersection and shone light on users who did not-more than a quarter of users. The trajectories of bicycle users that were questionably legal resulted in observed conflicts at both bidirectional intersections. Conflicts were grouped into three major observed themes: counterflow interactions, priority confusion, and directional awareness. Recommendations made in this paper aim to address each one of these observed themes with appropriate designs that are choreographic, prioritized, and predictable for all road users. Planners, engineers, and urban designers can gain significant insight into best-practice bicycle infrastructure through techniques, such as desire lines analysis, that observe behavior and design accordingly.
\end{abstract}

As interest in and discourse surrounding urban cycling have increased across the globe in the past decade, North American cities have been actively involved in this transportation shift. Although generally lagging behind their European counterparts, major cities in Canada and the United States have expanded their urban bicycling facilities and have seen a significant increase in bicycling modal share and government investment since the early 2000s (1). More recently, interest by North American cities in cycle tracks (protected on-street bicycle facilities) has gained considerable attention, inspired by the success of cities such as Copenhagen, Denmark, and Amsterdam and Groningen in the Netherlands, which have some of the highest bicycle modal shares and most extensive on-street protected bicycle lane networks. Studies in both Europe and North America point to cycle tracks as having the lowest injury risk factor of all types of bicycle facilities, as well as contributing to an increase in bicycle traffic and an accompanying

School of Urban Planning, McGill University, Suite 400, 815 Sherbrooke Street West, Montréal, Québec H3A 2K6, Canada. Corresponding author: A. El-Geneidy, ahmed.elgeneidy@mcgill.ca.

Transportation Research Record: Journal of the Transportation Research Board, No. 2662, 2017, pp. 102-115.

http://dx.doi.org/10.3141/2662-12 decrease in motor vehicle traffic (2, 3). Following Jacobsen's 2003 findings about safety in numbers, cycle tracks also arguably offer a promising opportunity for cities to increase their ridership numbers (and thus bicycle and pedestrian safety) through lowering a barrier to entry - the perceived danger of urban bicycling (4). Negative perception has been shown to be an important deterring factor for potential bicycle users, while cycle tracks have been rated as some of the most preferred, or positively perceived, bicycle infrastructure in surveys from Vancouver, British Columbia, Canada, to Copenhagen $(5,2,3)$.

Montreal, Quebec, Canada, currently has the oldest and most extensive network of cycle tracks in North America. Montreal currently has $82 \mathrm{~km}$ of protected on-street bicycle facilities within its overall bicycle network of $748 \mathrm{~km}$, which encompasses recreational trails, painted lanes, and designated shared streets (6). Although the city has announced the creation of a new $6-\mathrm{km}$ segment of unidirectional cycle tracks, the entirety of Montreal's existing protected network is made up of bidirectional paths located on one side of the street, separated from motor vehicle traffic by either concrete barriers or plastic bollards adjacent to a row of parking (7). In a local 2013 survey conducted by the Transportation Research at McGill (TRAM) group, respondents were asked to rate their feelings of safety for different types of bicycle facilities in the City of Montreal, at both midblock and intersection locations. Results showed that bicycle users felt safer using cycle tracks midblock than painted lanes or no infrastructure, but when located at intersections, bidirectional cycle tracks were perceived to be twice as dangerous (responses of "bad" and "very bad") — even more dangerous than painted lanes (Table 1).

Given that the perception of danger acts as an important deterrent to new bicycle users, it is important to understand why existing users perceive bidirectional cycle tracks negatively at intersections and to offer some strategies to decrease this negative perception. This research used the Desire Lines Analysis tool to perform a fine-grained analysis of bicycle user behavior through bidirectional intersections in Montreal in order to bring to light some of the reasons that may influence users' negative perceptions. It begins with a brief review of observational analysis methodologies used in the field of urban and mobility planning, and subsequently presents the methodology by which data were collected, treated, and analyzed for this study. The final sections examine the conflicts that arose in these intersections, providing design intervention recommendations and conclusions.

\section{BACKGROUND}

Observational analysis has been discussed and used as an effective tool for studying street life and human behavior in urban planning for several decades now (8). This discourse of observing patterns and 
TABLE 1 Perception of Infrastructure Types by Montreal Bicycle Users

\begin{tabular}{lcc}
\hline & \multicolumn{2}{c}{ Negative Perception (\%) } \\
\cline { 2 - 3 } Type of Bicycle Facility & Midblock & Intersection \\
\hline Arterial without facility & 57 & 46 \\
Painted bicycle lanes & 26 & 20 \\
Bidirectional cycle tracks & 17 & 33 \\
Calm residential street & 9 & 9 \\
\hline
\end{tabular}

NotE: Data from 2013 TRAM Montreal Cycling Behaviour Survey.

habits at the street level was launched into the American mainstream with the writings of Jane Jacobs in the late 1950s and early 1960s, which both critiqued and rebelled against top-down, theory-based city planning: "You've got to get out and walk. Walk, and you will see that many of the assumptions on which the projects depend are visibly wrong. . . . It is the premise of this article that the best way to plan for downtown is to see how people use it today; to look for its strengths and to exploit and reinforce them" (9).

In 1970, William H. Whyte formed a research group while working with the New York City Planning Commission-The Street Life Project, where he directly observed and documented people using public space in the city. This method of direct observation had previously been employed primarily in anthropological and ethnographic studies, but Whyte's work was seminal in bringing this form of analysis into the city space. In The Social Life of Small Urban Spaces, Whyte discussed the mandate under which his research group was originally formed - to study urban crowding-when in fact they often found through observation the opposite to be truemany public spaces suffered from vast emptiness (10). His research often also featured the placing of a camera for several hours at a high vantage point and recording time-lapse photographs of public space in order to map the locations and patterns of people. This early use of city observation enabled researchers to challenge long-held assumptions about how urban space is designed.

Since the 1970s, the work of Danish urban planner Jan Gehl has continued to formalize and canonize methods for observation in city spaces. His 2013 book, How to Study Public Life, co-written with Svarre, lays out various methodologies to understand context-specific issues in the parks, streets, playgrounds, and unidentified spaces of cities with a greater specificity than was described in Whyte's earlier work (8). Gehl's work has popularized both quantitative and qualitative methods of analysis in cities, such as pedestrian counts, pedestrian mapping, and documenting patterns of behavior. Operationally, many of the study methods used and discussed by Gehl have played an important role in the work of the traffic department in his hometown of Copenhagen. Pedestrian counts performed by the city in 1985 led to the redevelopment of the Strøget walking street in the city center (11). A thorough methodology of observational techniques applied to bicycles has also allowed Copenhagen to develop what is arguably one of the world's most comprehensive urban bicycle networks, with nearly 400 kilometers of on-street cycle tracks (12). This has been accomplished through interventions such as widening cycle tracks, on the basis of observed capacity issues, or changes in intersection striping to facilitate heavy left-turning bicycle flows.
Many North American and European cities today have installed automated bicycle and pedestrian counters and employ some method of manual counting, with varying degrees of success. The City of Montreal currently uses data from 21 automated bicycle counters (generally magnetic loop counters in pavement) to understand overall bicycle flows and citywide displacements of bicycle users. Researchers have been able to use this macrolevel data to articulate patterns at the urban scale, from temporal trends to impacts of weather on bicycling (13). However, beyond this high-level analysis, there has been a lack of understanding of how bicycle users interact on the ground with the design of infrastructure, especially at intersections, which have been found to be the most collision-prone element of a road network (14). In its bicycle urbanism consultancy, Copenhagenize Design Company began employing a new observational analysis methodology, dubbed desire lines analysis, in 2012, to begin building a body of knowledge on bicycle user behavior. This was primarily accomplished with the collection and analysis of hours of video footage from intersections that were undergoing study, identifying important indicators to track throughout the session. As a fine-grained analysis, this observational methodology traces the movements of bicycle users through an intersection, much like the pedestrian tracing techniques Jan Gehl employed in studying public space (10). The resulting "desire lines" show where bicycle users choose to ride, both where they are legally permitted to ride and where they are not, offering new insights into the potential disjunction between the infrastructure design and behavior of bicycle users. Since 2012, desire lines analysis has been performed at numerous intersections in Copenhagen and in Amsterdam. It is intended to continue this work in a global study and compare the interaction of bicycle user behavior with infrastructure types across the world (15-17). This study in Montreal serves as the first investigation of on-street bidirectional cycle tracks.

\section{METHODOLOGY}

To identify candidate intersections to study in the City of Montreal, the $748 \mathrm{~km}$ of bicycle facilities on the island were segmented into their component elements: $271 \mathrm{~km}$ of recreational or off-street paths, $214 \mathrm{~km}$ of painted on-street bicycle lanes, $181 \mathrm{~km}$ of shared or marked streets, and $82 \mathrm{~km}$ of protected on-street cycle tracks (6). These final 82 kilometers of bicycle facilities were plotted out spatially and given 50-m buffers at each intersection point. These buffers served as catchment areas for the responses of surveyed bicyclists (from the 2013 TRAM survey), in which they were asked to place a pin on the intersection in Montreal they felt was most in need of improvement. Of the 1,280 recorded points of concern from respondents, those intersections that touched or were near (10 $\mathrm{m}$ away) a protected on-street bicycle facility with five or more pins were logged and recorded. These results were then overlaid with geolocated 2013 and 2014 bicycle collision data, from the Société de l'Assurance Automobile du Québec, that recorded the number of collisions to fall within each of the previously logged 50-m intersection buffers. The results of this intersection selection process can be seen in Figure 1.

Among the final selection of intersections, types of road configurations were grouped together (e.g., two intersecting one-way streets, with one bidirectional cycle track, are denoted with a letter in the rightmost column in Figure 1), to further identify subtleties between intersections that might influence the behavior of bicycle users. The two final intersections selected for this study held the highest score for perception of danger by bicycle users and the highest bicycle collision count for intersections with protected bidirectional facilities, 


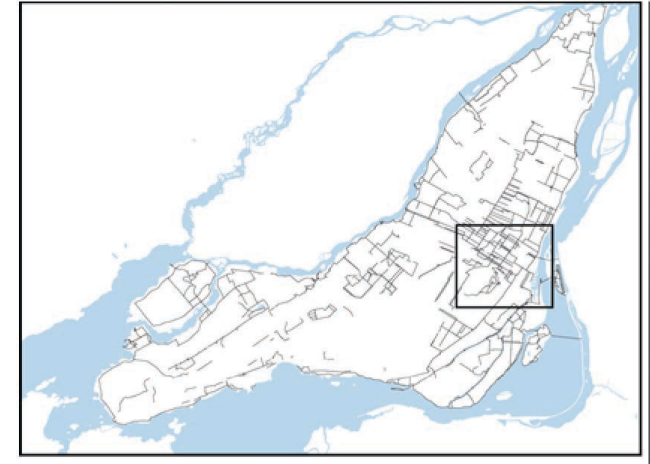

(a)

\begin{tabular}{|r|l|l|l|}
\hline INTERSECTIONS OF INTEREST & $\begin{array}{l}\text { Perception } \\
\text { of Danger }\end{array}$ & $\begin{array}{l}\text { Accident } \\
\text { Count }\end{array}$ & Type \\
\hline Berri and Cherrier & $\bullet \bullet \bullet \bullet \bullet$ & $\bullet \bullet$ & A \\
\hline St. Urbain and de Maisonneuve & $\bullet \bullet \bullet$ & $\cdots \cdots \bullet \bullet \bullet$ & B \\
\hline Rachel and Papineau & $\bullet \bullet \bullet$ & $\cdots \cdots$ & C \\
\hline Rachel and St. Denis & $\bullet \bullet \bullet$ & $\cdots \cdots \bullet$ & C \\
\hline Berri and Ontario & $\bullet \bullet \bullet$ & $\cdots \cdots \bullet$ & C \\
\hline University and de Maisonneuve & $\bullet \bullet \bullet \bullet$ & & D \\
\hline du Fort and de Maisonneuve & $\bullet \bullet \bullet$ & $\bullet \cdots \bullet \bullet$ & E \\
\hline Guy and de Maisonneuve & $\bullet \bullet \bullet$ & $\bullet \bullet$ & E \\
\hline St. Laurent and Van Horne & $\bullet \bullet \bullet \bullet$ & $\cdots \bullet$ & F \\
\hline
\end{tabular}

(b)

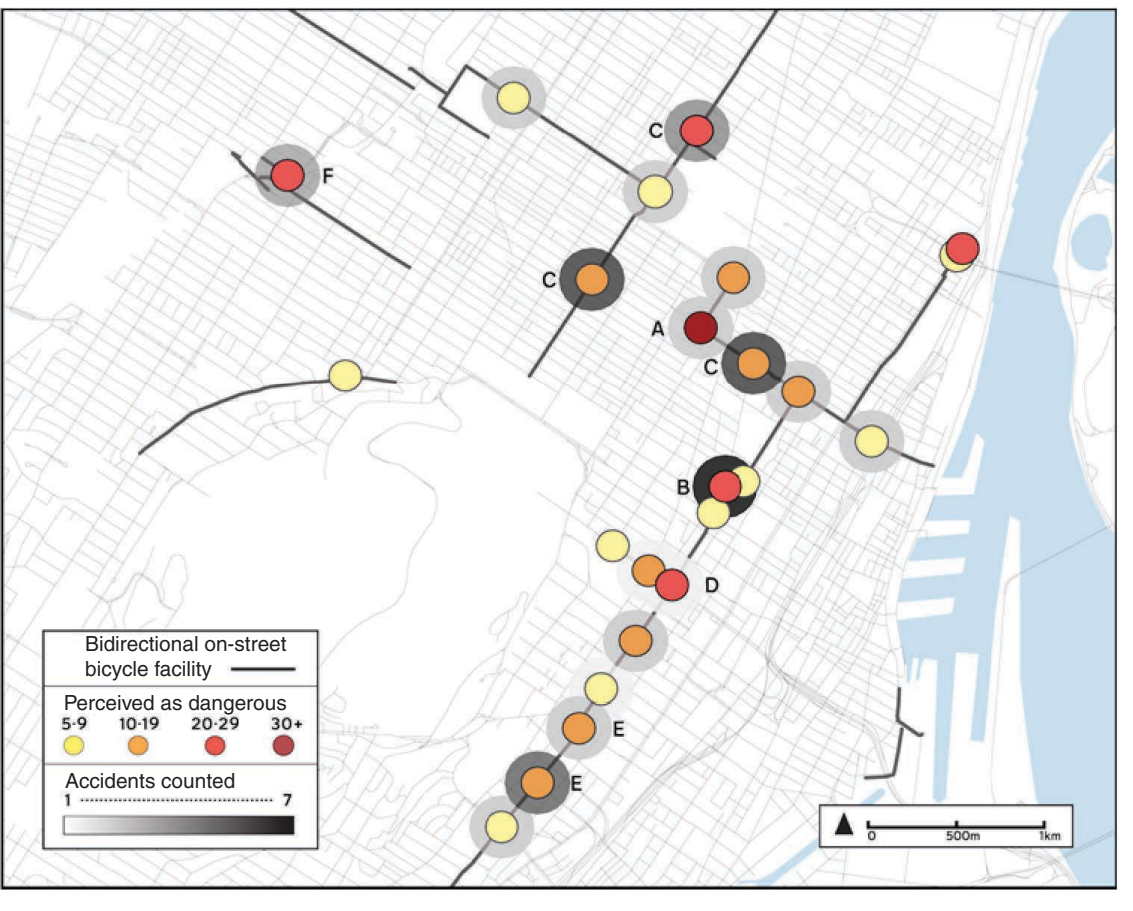

(c)

FIGURE 1 Bidirectional cycle track intersection selection in Montreal.

respectively. Figure 2 shows the details of these intersections and the vantage points from which they were recorded. Each intersection also has a unique road configuration for intersections with bidirectional cycle tracks, allowing an analysis of these cycle tracks within different physical contexts.

The first intersection is Berri and Cherrier Streets, which had the highest negative perception for bidirectional cycle tracks in the city. It consists of two intersecting two-way streets and two intersecting cycle tracks. There are painted bicycle lanes on the north side of Berri Street (shown in red), as well as two bicycle signals in the north-south direction that allow bicycles to cross in both north and south directions when motor vehicles are given a straight green arrow. The bicycle tracks meet on the northwest corner of the intersection in a painted waiting box protected by plastic bollards, next to which there is a BIXI (Montreal bikeshare) station. There are bicycle-crossing marks in both directions, but they have mostly faded out on the pavement. On the south side of Berri Street, the road dips down into an underpass and the cycle track follows.

The second intersection is Saint Urbain Street and de Maisonneuve Boulevard, which saw seven official bicycle collisions between 2013 and 2014 - the highest number for intersections with bidirectional cycle tracks in the city. It has two intersecting one-way streets and only one bidirectional cycle track along de Maisonneuve Boulevard. There is a painted southbound bicycle lane on Saint Urbain Street, with a green bicycle box that also functions as a bus stop, and faded bicycle crossing markers appear on the pavement. This intersection has the extra complication of another street bisecting Saint Urbain Street; on one side, it is a two-way street (Ontario Street), and on the other, it switches to one-way, becoming President Kennedy Avenue on the west side.

\section{DATA COLLECTION}

Each intersection was filmed from a vantage point (Figure 2) on Tuesday, May 24, and Wednesday, May 25, 2016. In Figure 3, the 2015 average monthly bicycle counts on Berri Street from an automatic counter for the City of Montreal are plotted against the local median temperature of the same year, demonstrating that the month of May can be seen as the start of the significant biking season in Montreal (data sources were the City of Montreal and Environment Canada; counter data were not available for December). Yearly counting profiles of other major streets in the city follow a similar profile, with significant numbers of bicycle users beginning to rise in May.

On each weekday of filming, video cameras recorded six hours of footage: morning rush hour (7:30 to 9:30 a.m.), midday (2:00 to 4:00 p.m.), and evening rush hour (4:30 to 6:30 p.m.). Both days saw warm summer weather in the range of $20^{\circ} \mathrm{C}$, with $10 \mathrm{~min}$ of rain in the evening of May 25. The results and subsequent analysis portray the observed movements, flows, conflicts, and indicators from these two intersections.

\section{RESULTS}

In total, 12 hours of video footage were analyzed in detail, recording and focusing on the following observations:

- Desire lines: the paths taken by bicycle users;

- Bicycle conflicts: collisions, near misses, bunching, awkward maneuvers, and confusion;

- Gender split;

- Children on bicycles alone or with parents;

- Presence of helmets; 

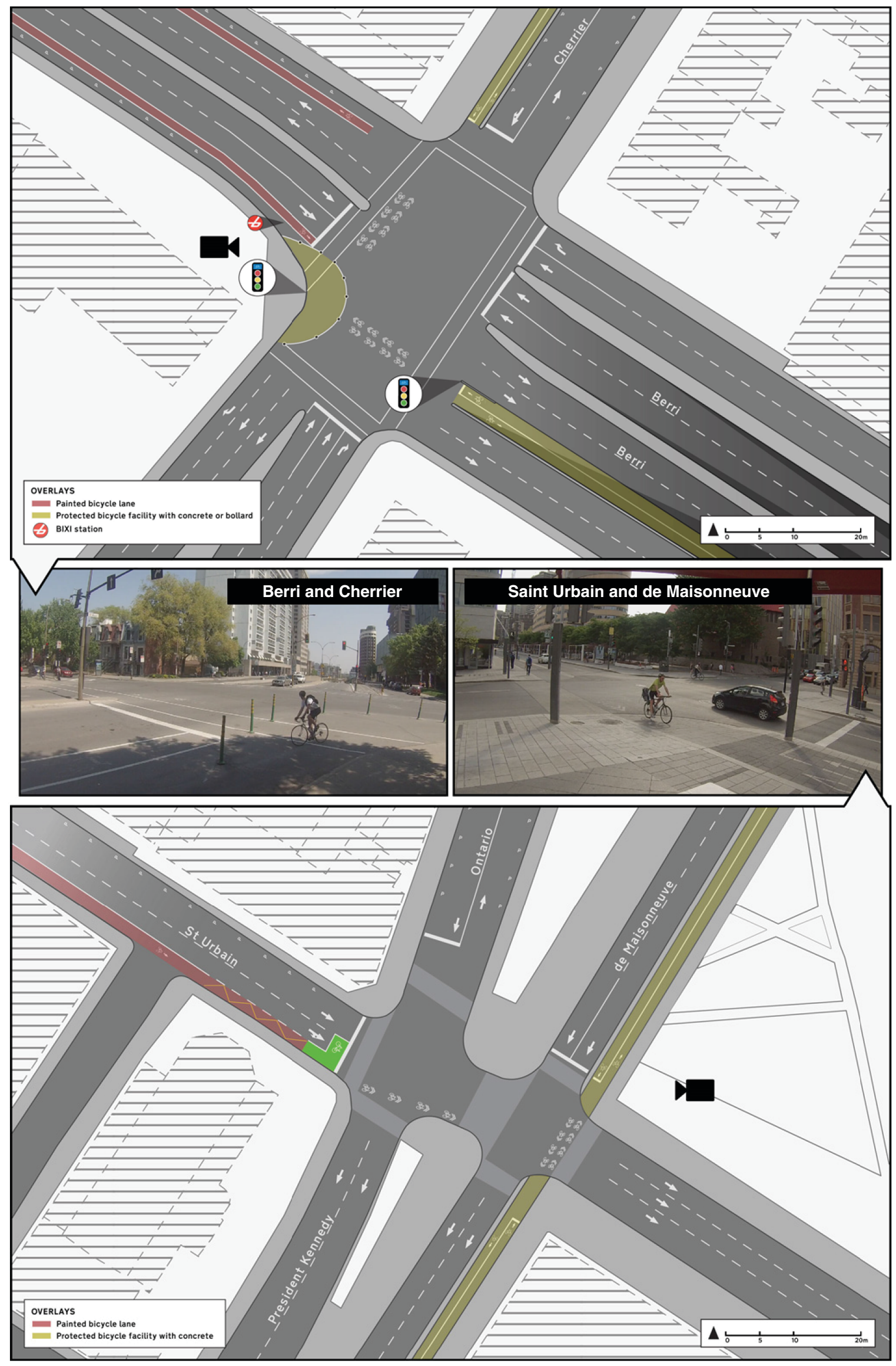

FIGURE 2 Final intersection selections with bidirectional cycle tracks. 


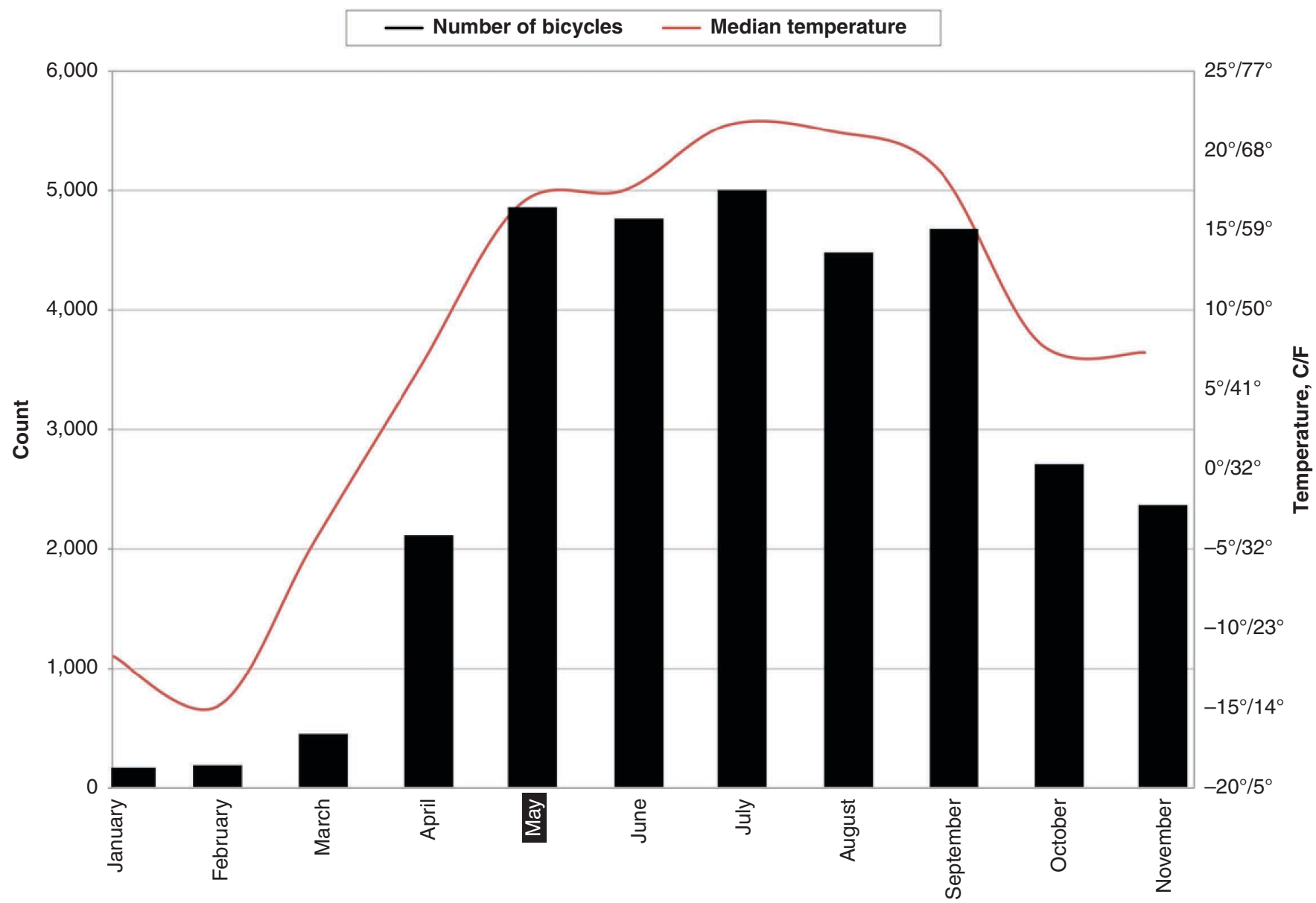

Month

FIGURE 32015 monthly bicycle counts on Berri Street and Montreal weather profile.

- Presence of personal versus public bicycles (BIXIs);

- Presence of cargo or delivery bicycles; and

- Red lights run by bicycle users.

The resulting desire lines for the intersection of Berri Street and Cherrier Street can be seen in Figure 4. All in all, 4,080 bicycle desire lines were observed passing through the intersection of Berri and Cherrier, $60 \%$ of which belonged to male riders and $40 \%$ to female riders; $18 \%$ of bicycles observed were BIXIs; $60 \%$ of users wore helmets. The most prominent path taken was Desire Line C. This path accounted for $25 \%$ of total bicycle movement as users came from the east to take the Berri Street bicycle track southboundthis is one of the few north-south protected bicycle routes in the city. The second most prominent movement, Desire Line $S$, is the inverse of Desire Line C, with $17 \%$ of users taking this path heading northbound on Berri Street and turning right in the waiting box eastbound toward the Cherrier Street cycle track. That these two movements carry high volumes is not surprising as the design of the intersection leads users this way. What is interesting is that, when one follows the movements of Desire Lines D, Q, and R, it can be seen that another $25 \%$ of users opted for questionably legal paths to avoid the box turn that is prescribed by the current design. Around $4 \%$ of users (149 riders) directly broke the law by running red lights, but it is the questionably legal nonconforming desire lines that are interesting and important in understanding how conflicts arise.
The resulting display of desire lines for the intersection of Saint Urbain Street and de Maisonneuve Boulevard can be seen in Figure 5. At this intersection, 4,470 bicycle desire lines were observed passing through the intersection of Saint Urbain Street and de Maisonneuve Boulevard, $59 \%$ of which belonged to male riders and $41 \%$ to female riders, while $23 \%$ of bicycles observed were BIXIs and $55 \%$ of users wore helmets. Of the three most prominent desire linesA, G, and L-each accounts for $19 \%$ to $20 \%$ of the total bicycle movement here. These three desire lines are all straight-through movements heading south, east, and west. Apart from Desire Line N, which accounted for $13 \%$ of movements, the remaining 13 desire lines together (each with less than $6 \%$ of movements) represent 1,258 users - the remaining $28 \%$. Some of these movements fall in a legal gray zone, where users did not explicitly break the law but ended up using the intersection in a way other than intended by the design. Only 90 users (2\%) were observed explicitly running red lights. The following section presents the conflicts observed in both intersections with a discussion of what might have caused them, followed by design recommendations and conclusions.

\section{CONFLICT ANALYSIS}

Along with the series of observed indicators noted earlier, bicycle conflicts were observed at both intersections as desire lines converged at various points. To reiterate, for this study a bicycle conflict was 


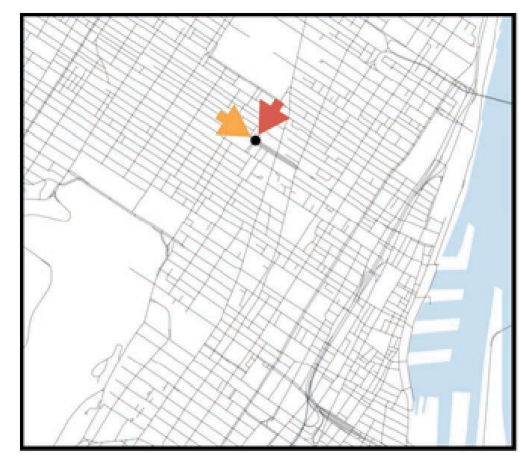

(a)

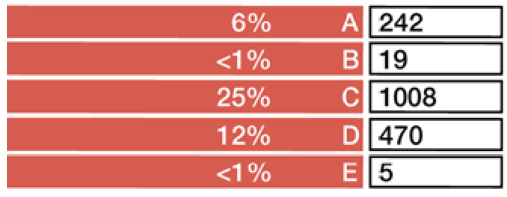

(b)

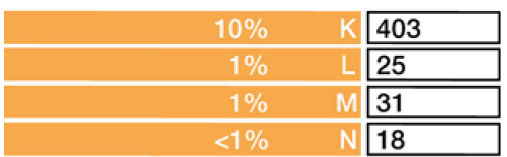

(c)

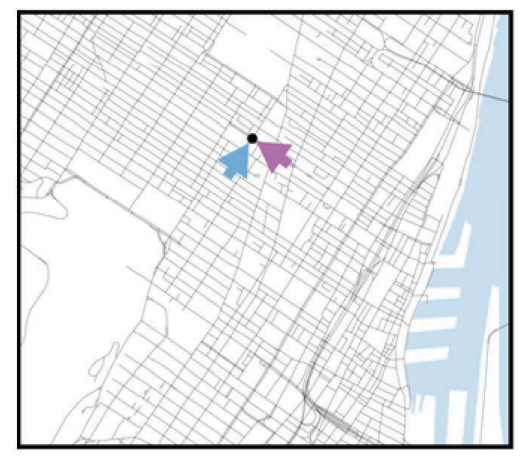

(e)

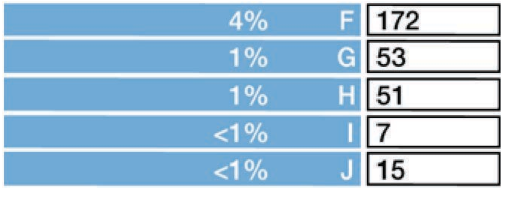

(f)

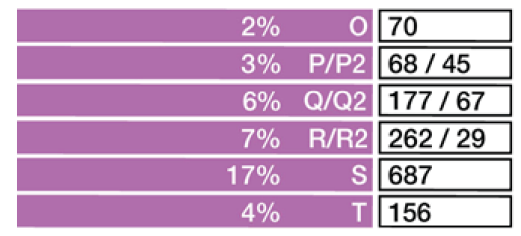

(g)

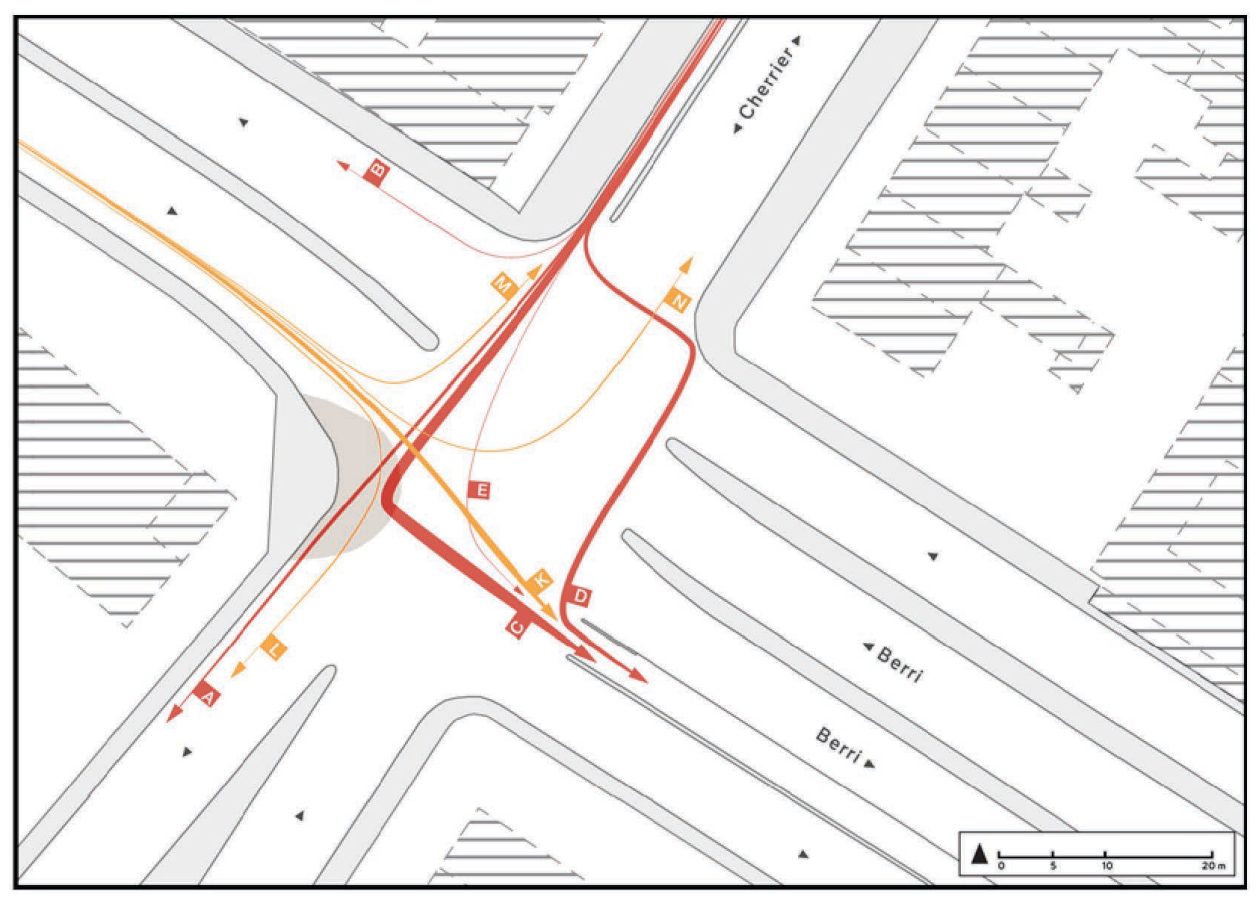

(d)

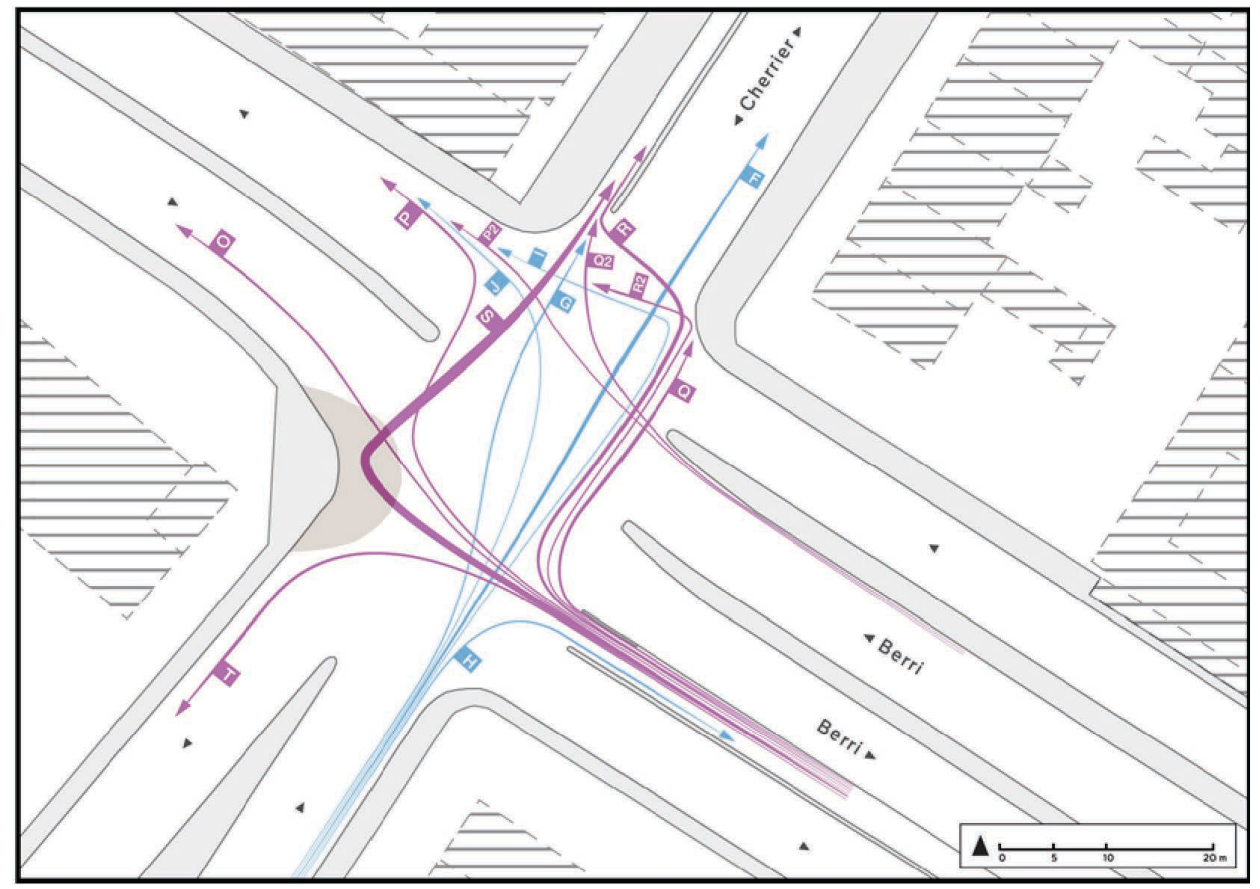

(h)

FIGURE 4 Desire lines observed at Berri and Cherrier Streets on May 24, 2016. 


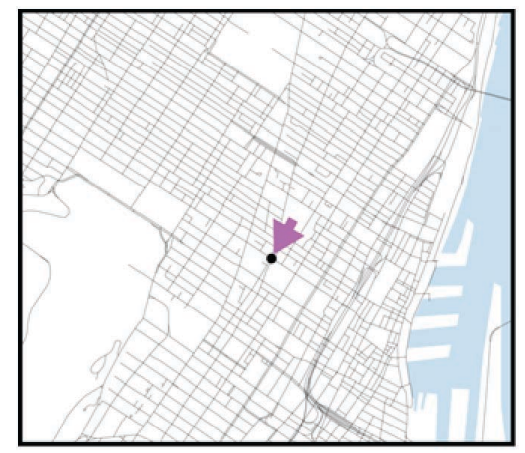

(a)

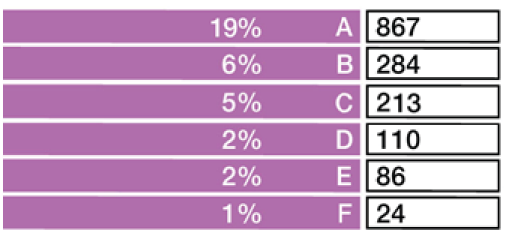

(b)

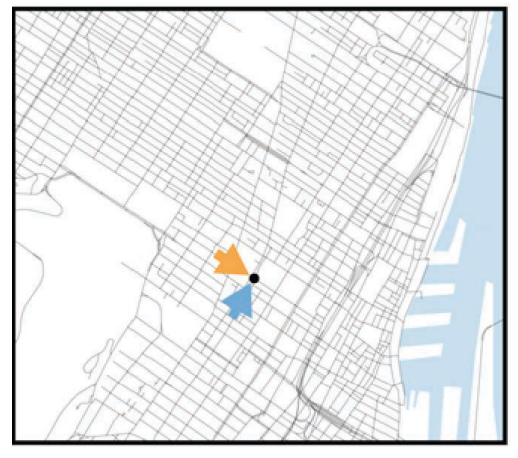

(d)

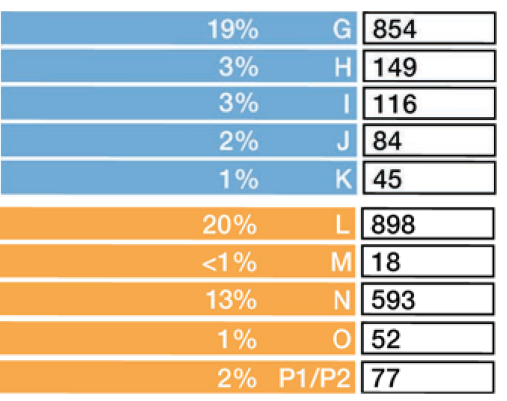

(e)

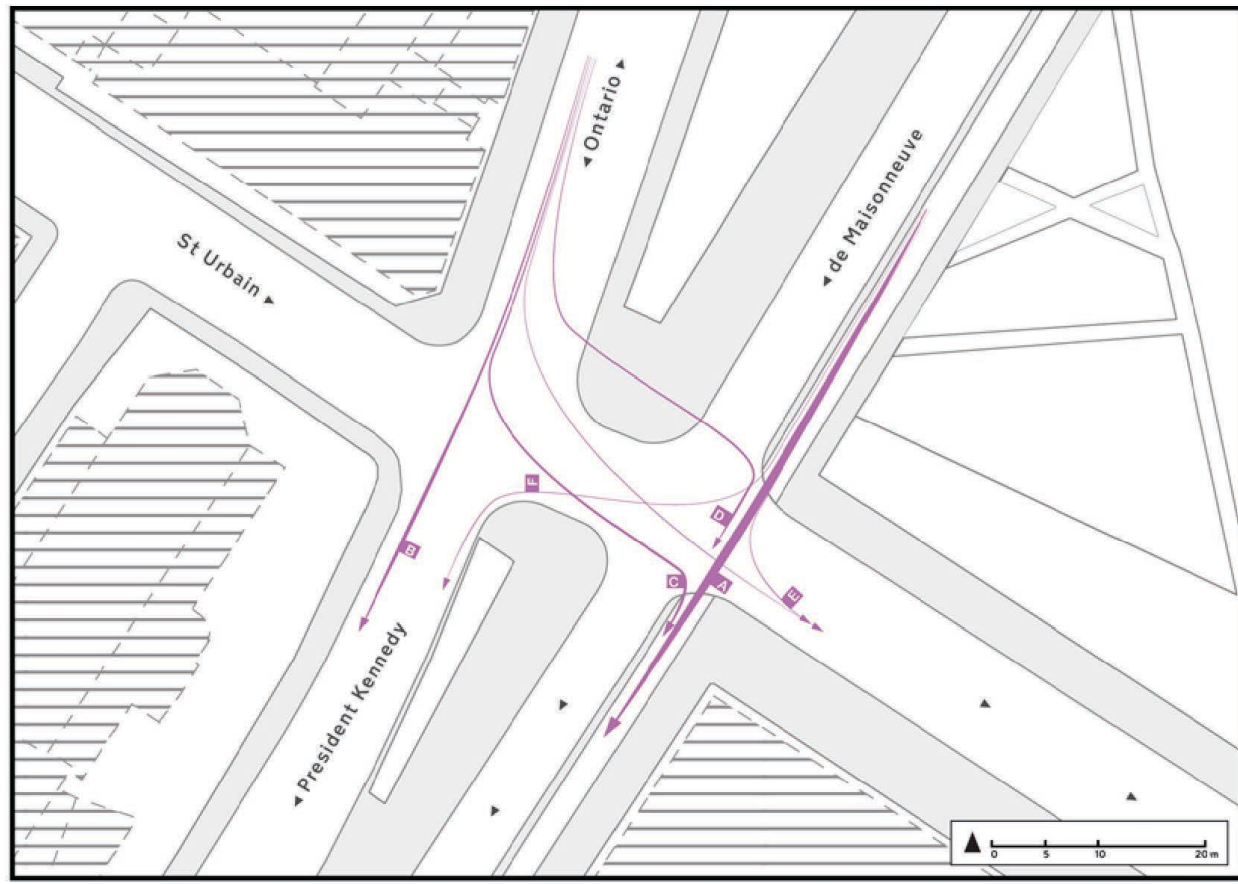

(c)

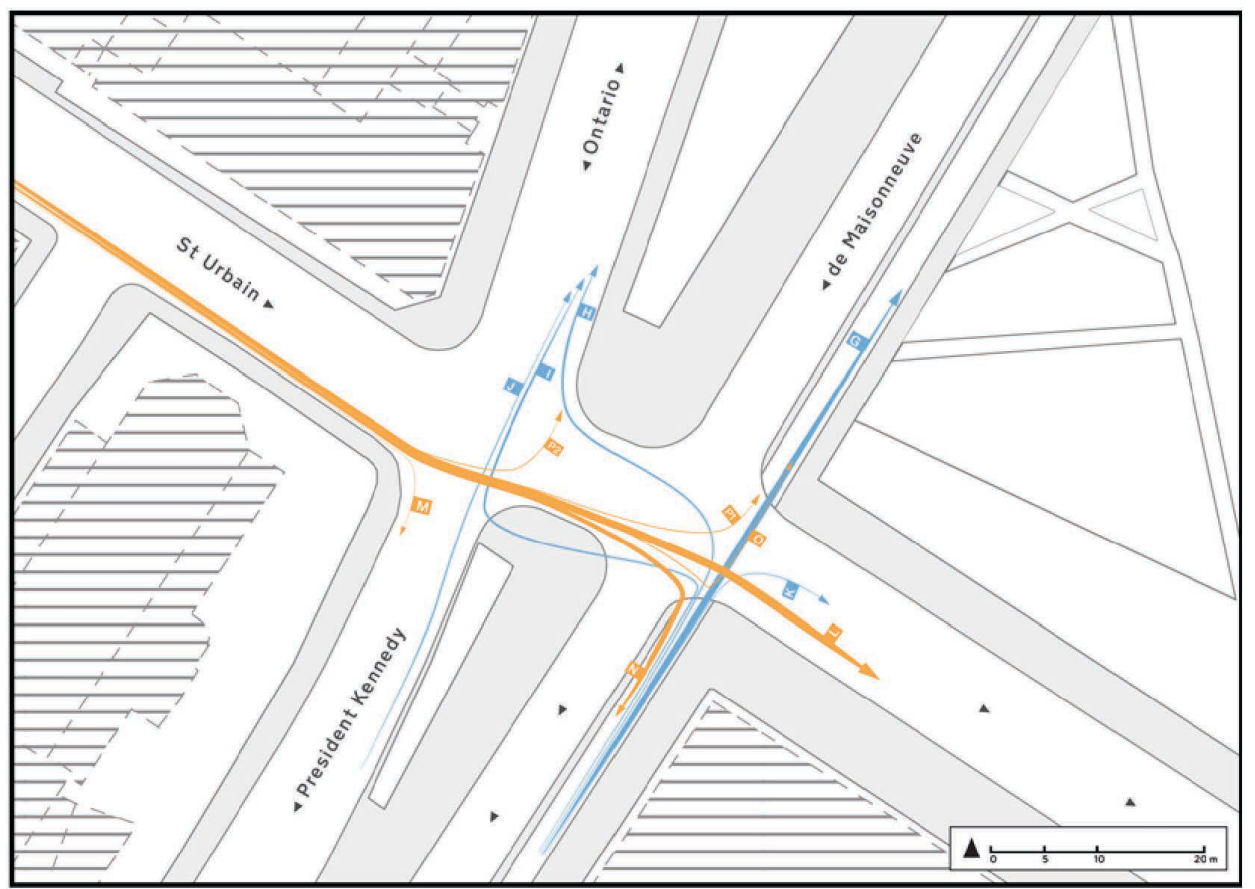

(f)

FIGURE 5 Desire lines observed at Saint Urbain Street and de Maisonneuve Boulevard on May 25, 2016. 
defined as an observed bicycle collision, a near miss, bunching, an awkward maneuver, or confusion with another bicycle, pedestrian, or motor vehicle. Overall, three types of scenarios were identified that generate conflict: counterflow interactions, priority confusion, and directional awareness. The example in Figure 6 falls into the first category of counterflow interactions, where the design of the intersection guides two counter-directional flows together at certain points where conflict is generated. The second type of scenario-priority confusion - can be observed when bicycle users and pedestrians do not have a clear understanding of where each is to wait at the corner of the intersection, which leads to bunching, blocking, and the potential for collision. The third type of scenario-directional awarenessconcerns the desire lines that take legally questionable routes; these bicycle users surprise other bicycle users, pedestrians, and motorists by appearing where they were not expected, leading to conflict.

Figure 6 demonstrates one example of north-south bunching that was observed with the convergence of Desire Lines C, E, K, O, P, S, and T. Northbound and southbound bicycle users were forced to slow down and awkwardly maneuver around each other because of the significant number of other bicycles trying to get through this pinch point. Some northbound users were pushed to their right, which put them in a dangerous place near the path of southbound motor vehicle traffic. Observations such as this one were compiled and logged with all subsequent observed conflicts to produce a typology of conflict for each intersection that would serve to better explain how bicycle users interact with the infrastructure design.

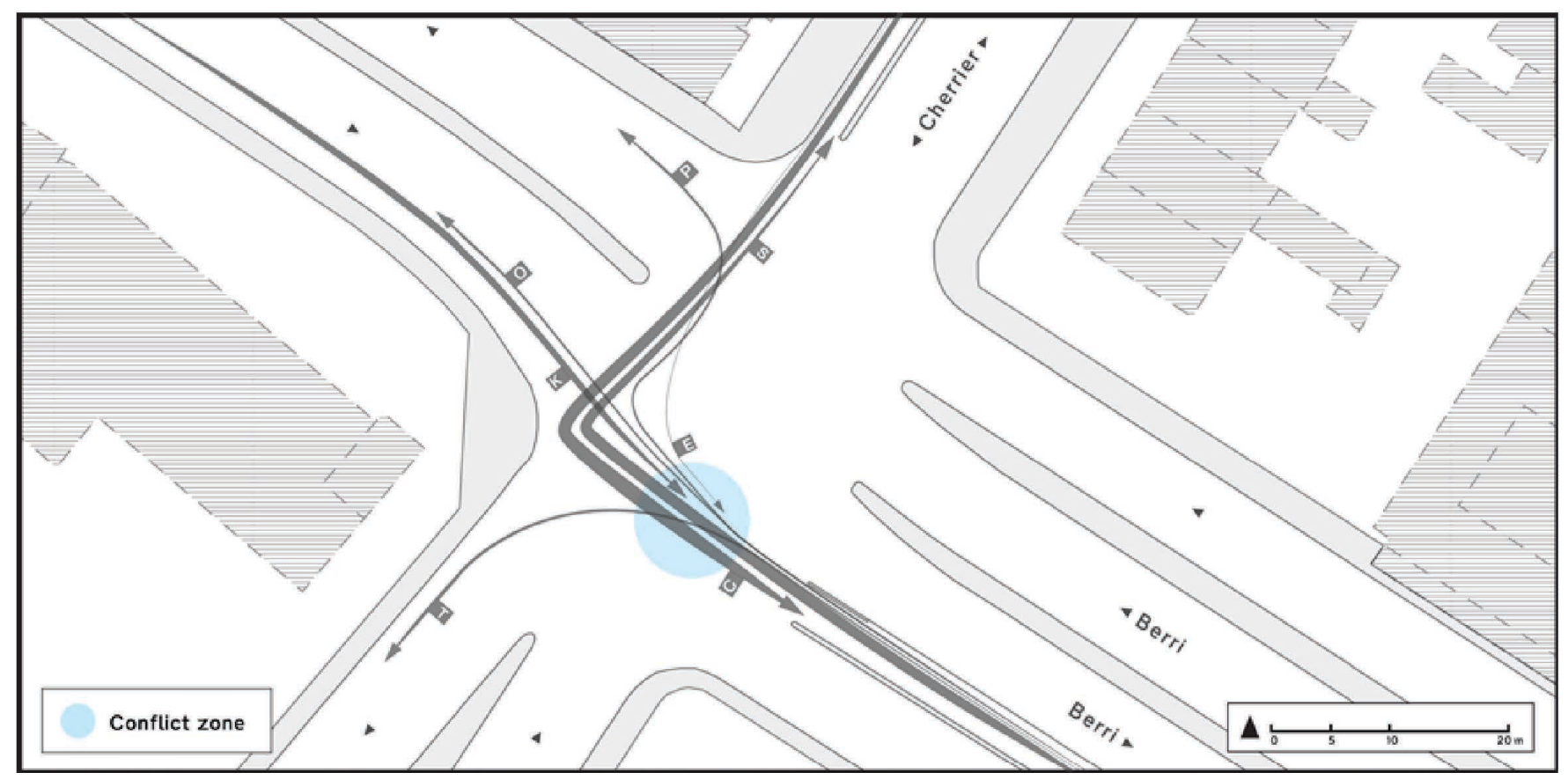

(a)

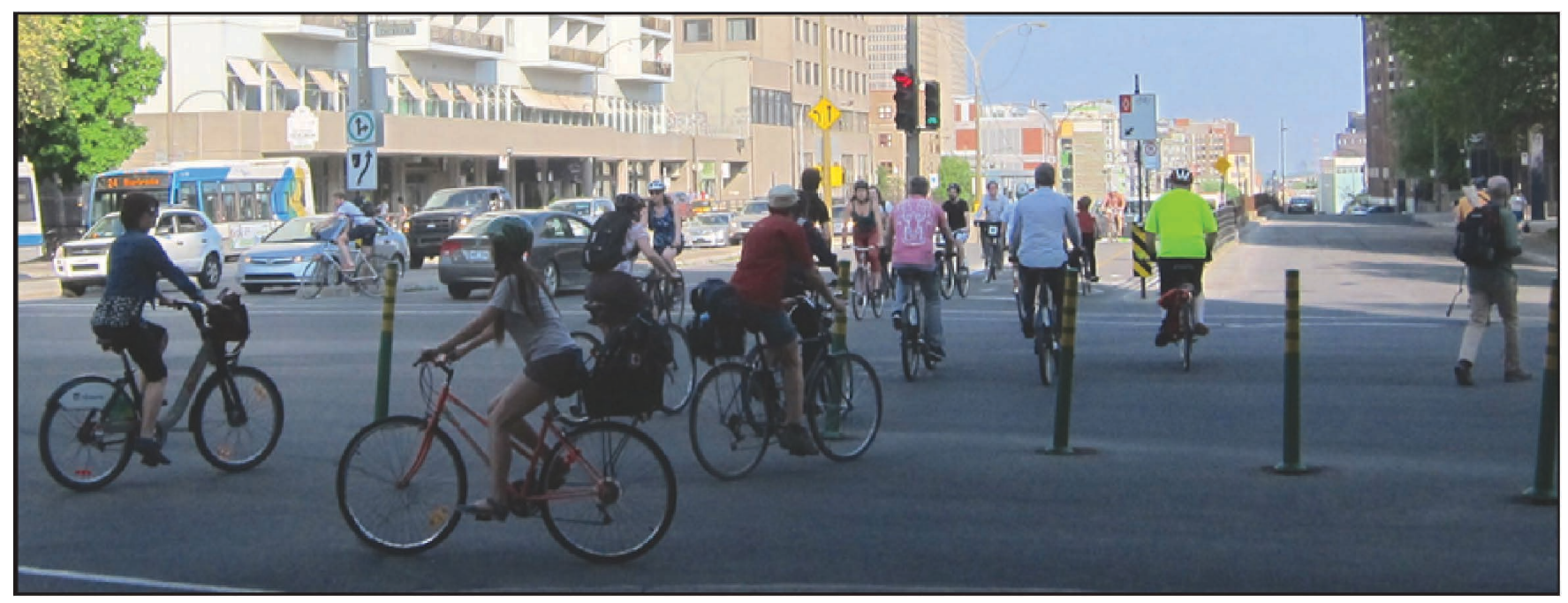

(b)

FIGURE 6 Desire lines converging and generating conflict. 
The observed conflicts at Berri and Cherrier Streets can be seen in Figure 7, divided by type and frequency, with an example of each for the sake of clarity. The observed conflicts at Saint Urbain Street and de Maisonneuve Boulevard can be seen in Figure 8, divided into type and frequency, with examples of each. (For a full list of observed conflicts for the intersections presented in Figures 7 and 8, please write to the corresponding author.)

\section{DISCUSSION OF STUDY}

The development of a conflict typology in the previous section shed light on the common themes observed while examining bicycle user behavior at both intersections in this study with bidirectional cycle tracks. To understand why bicycle users in Montreal are negative about intersections with bidirectional cycle tracks and negative about these two intersections in particular, it is important to emphasize these observed themes and offer recommendations for improvements in the street design. To reiterate, the identified conflict types were counterflow interaction, priority confusion, and directional awareness. If each of these describes an issue that generates conflict in the intersection, then it might be fruitful to offer recommendations and design interventions that address each particular issue.

First, counterflow interaction conflicts were observed as issues largely of capacity-bicycle users were forced to travel in two directions within the confines of one bicycle track. Often, there was excessive bunching or awkwardness because of too many users attempting to move past other users heading in the opposite direction. It would stand to reason that separating these two directions into their own spaces and ensuring that there are sufficient east-west and north-south routes within an urban area would spread out users and ease these conflicts. From these observed conflicts, it is recommended that the construction of protected cycle tracks follow a choreographic design, where opposing directions of traffic are given their own protected space, with the observed desire line trajectories influencing their interaction.

Secondly, priority confusion conflicts seemed to arise either from a lack of clarity in the street design of how each transport mode should move or from a disjunction between the infrastructure design and the mobility desires of users. When bicycle users, pedestrians, and motorists did not have a common understanding of where to wait for signal changes, they would accidentally block one another, causing bunching, near collisions, and confusion. Design interventions for this type of conflict should seek to separate transport modes physically and temporally at complex intersections, offering priority and safety to the more vulnerable road users-that is, to pedestrians and bicycles. Designs may also be employed that create incentives and promote behavioral change with timing, spacing, and sight lines.

Last, directional awareness conflicts were observed in scenarios where road users were surprised by the arrival of a bicycle from an unanticipated direction. These surprising encounters seemed to be some of the most dangerous as they tended to be noticed only when users were already in motion - turning a corner or in a blind spot. One recommendation to avoid these conflicts would be to keep all fastermoving transport modes following the same directional logic; that is, if motorists travel on the right side of the street and subsequently turn right, so should bicycle users. Observing desire lines brings awareness to the conflicts generated by unexpected movements and suggests that intersections should follow a design that is predictable for all users.

\section{RECOMMENDATIONS}

Figures 9 and 10 offer design recommendations for both of the intersections in this study, aiming for a reduction in the number of conflicts and an improvement in the perception of these junctions. The suggested interventions follow the assertions made in this discussion and aim to design intersections that are choreographic, prioritized, and predictable. It should be remembered that these figures are conceptual in their motives - they seek to address observed conflicts through adjustments in the street design and showcase how that might manifest itself on the ground. These intersections would require a more thorough investigation and adaptation before proceeding with infrastructural adjustments.

\section{Choreographic Design for Berri and Cherrier}

The first design intervention recommended here is the separation of cycle tracks into unidirectional facilities on each side of the road. As all intersecting roads here are two-way, with motor vehicles on the right side, so too are the cycle tracks. Conflicts observed with bunching can be avoided as bicycle track capacity has doubled here, with different directional flows of traffic being separated on different sides of the street. Cycle tracks should be wide enough (Copenhagen's minimum is $2.2 \mathrm{~m}$ ) so that slower users can stay to the right and faster users can comfortably pass them. This way, all streams of movement can interact as smoothly as possible. An additional recommendation is to increase the number of nearby protected east-west and north-south protected bicycle corridors to alleviate any further capacity issues.

\section{Prioritized Design for Berri and Cherrier}

One of the most noticeable elements of this new design is the increased presence of bold markings and signals. One of the major observed conflicts here was a blocking and bunching conflict between bicycle users and pedestrians; highly visible pedestrian and bicycle crossing markers clearly demarcate where each transport mode shall move. As noted, bunching is improved because of the presence of unidirectional cycle tracks, but the placement of stop lines and crossing markers ensures clarity for users waiting at each corner. For example, because this intersection will continue to see heavy southbound flows from the east (Desire Line C), pedestrian crossings and southbound stop lines were both pulled back, to create sufficient waiting space for these left-box-turning bicycle users. Additionally, all motor vehicle stop lines are pulled back from the bicycle stop lines to ensure that vulnerable users are visible and given priority; bicycle signals with prioritized phases have also been implemented at all four bicycle stop lines. Because bicycle and vehicular signals are placed on the approaching side of an intersection, users are required to remain at the stop line in order to see their respective signals before proceeding into the intersection.

\section{Predictable Design for Berri and Cherrier}

These design interventions eliminate the possibility of observing Desire Lines D, Q, and R, as bicycle users heading northbound on Berri Street will be approaching on the far right side of the underpass, on a protected unidirectional cycle track. These identified desire lines created nearly all of the lack of directional awareness in this study 


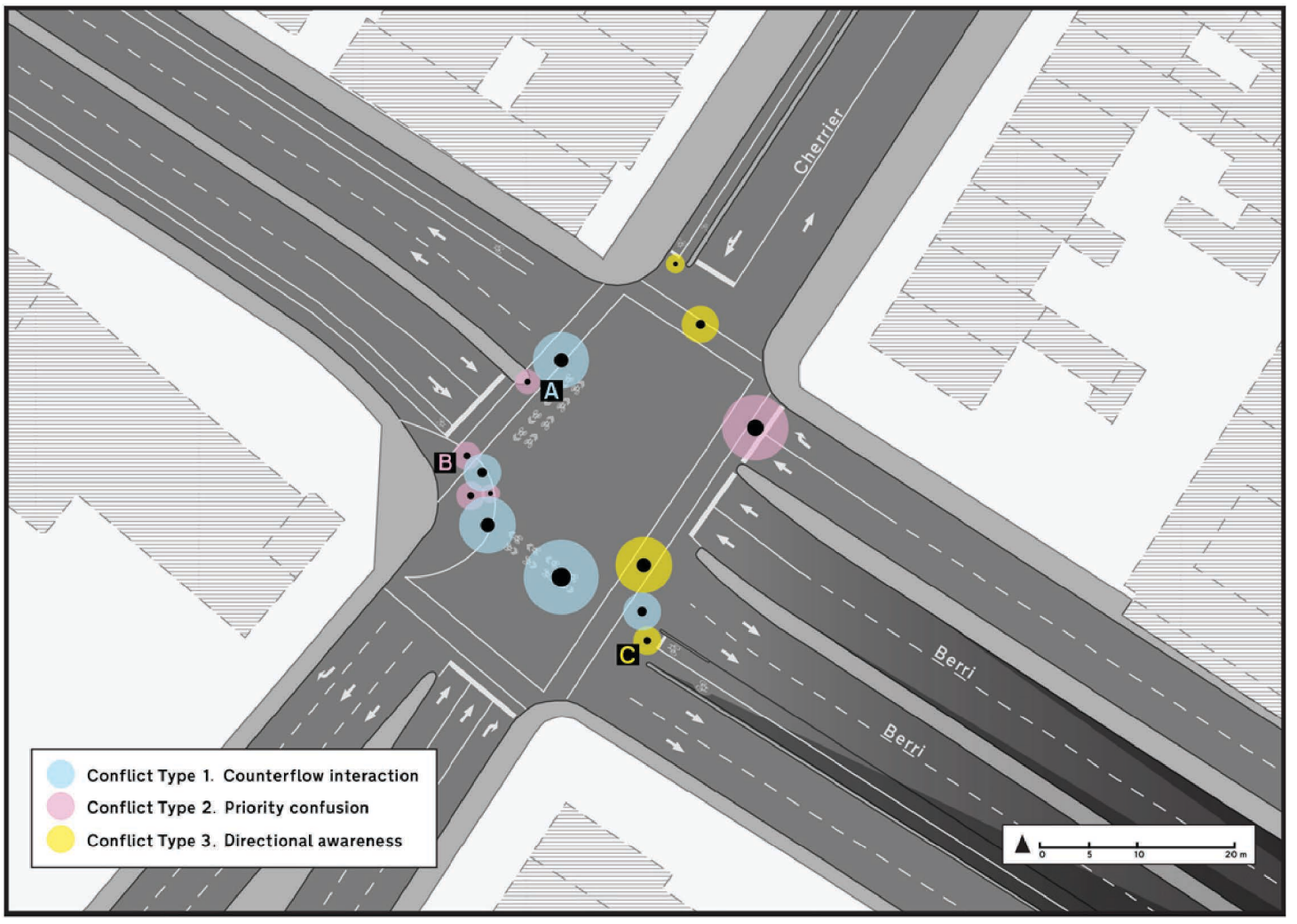

(a)

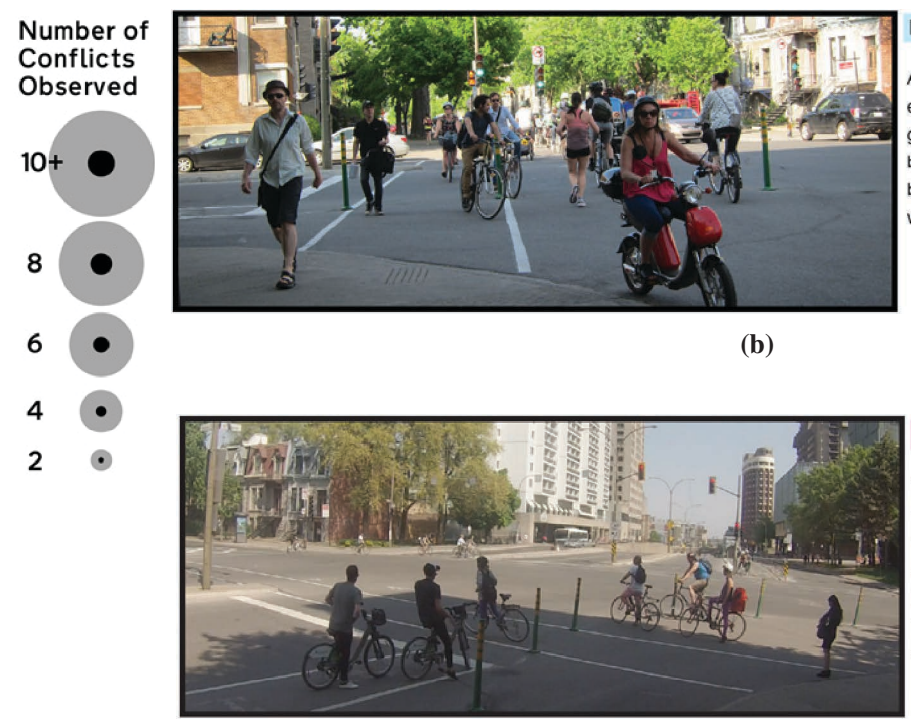

Example A. Counterflow interaction

As bicycle users cross the north side of Cherrier east and west, the interaction between large groups of bicycles in two directions generates bunching, awkward maneuvers, and near collisions between bicycle and pedestrians. This scenario was observed six times.

(c)

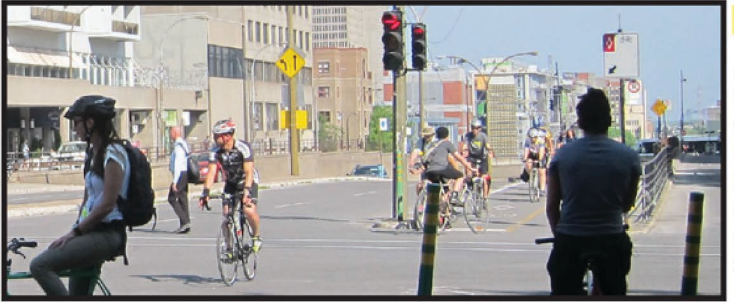

Example C. Directional awareness A substantial number of bicycle users took a less-than-legal route from the east to get to the southbound cycle track on Berri Street. Northbound users waiting for the light to change can be seen here surprised by bicycles approaching from their right, the east, where they do not anticipate it. This scenario was observed three times as well as several encounters with pedestrians and motorists.

(d)

FIGURE 7 Conflict typology and examples at Berri and Cherrier Streets. 


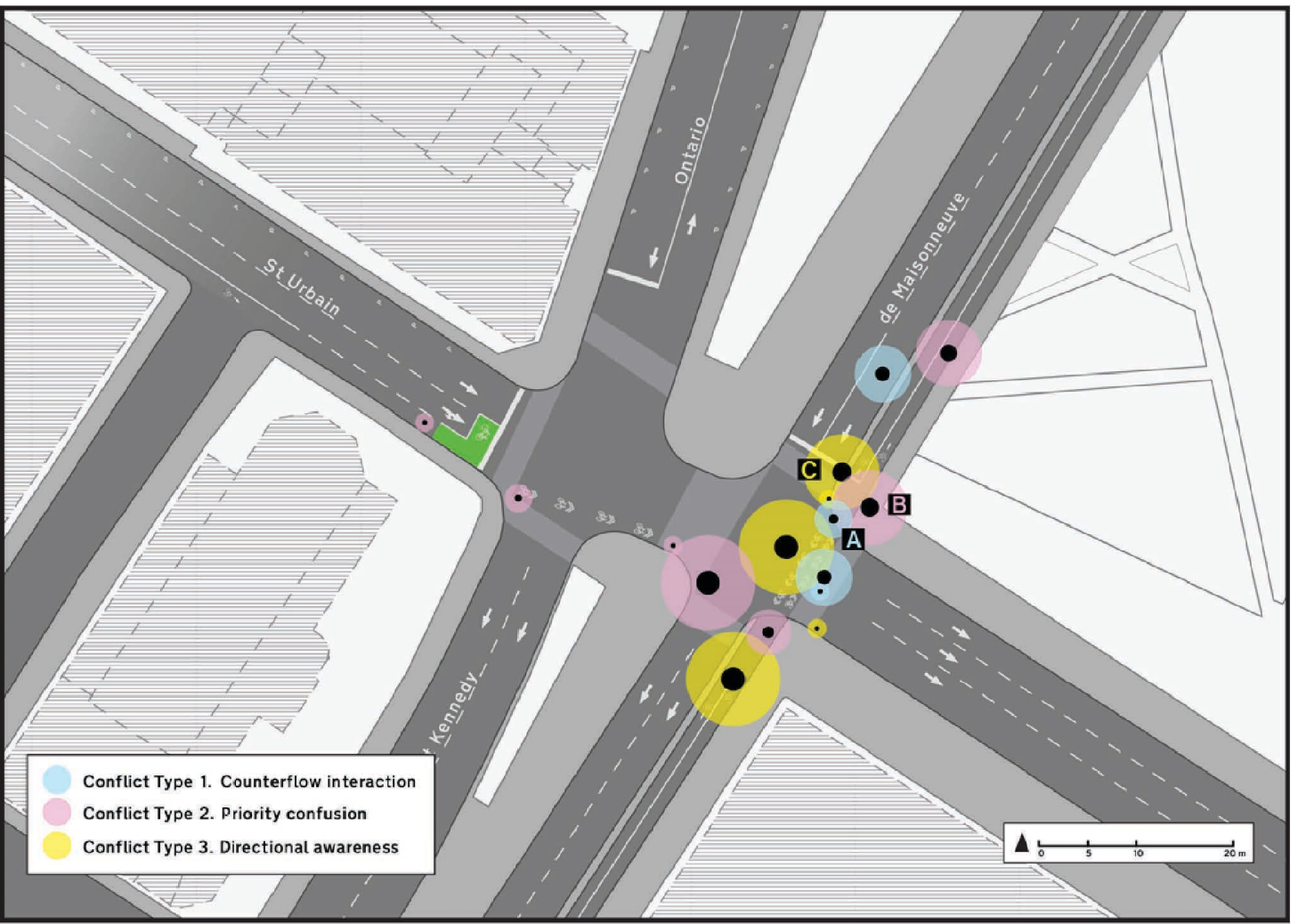

(a)

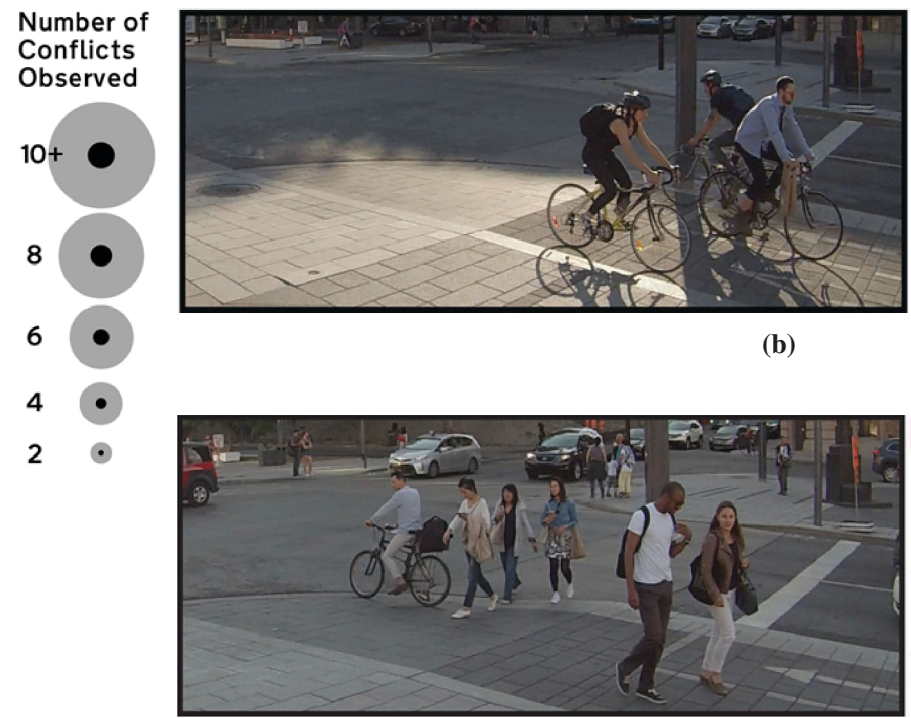

Example A. Counterflow interaction

As the protected cycle track here is bidirectional, instances of bunching and near hits occur between opposing directions of bicycle users. Here, an eastbound user is trying to pass another while entering the allotted space for westbound users. This scenario was observed four times at this corner and six times at midintersection locations.

(c)

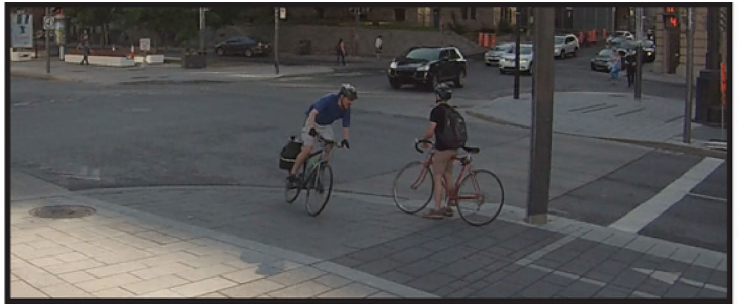

Example C. Directional awareness

With the bidirectional cycle track being placed to one side of the road, bicycle users who desire to get to the far side will cut corners at both the east and the west corners of the intersection. Here a user making a less-than-legal movement surprises a westbound user who also happens to be ahead of the stop line. This scenario occurred at the east corner eight times and 12 times on the west side.

(d)

FIGURE 8 Conflict typology and examples at Saint Urbain Street and de Maisonneuve Boulevard. 


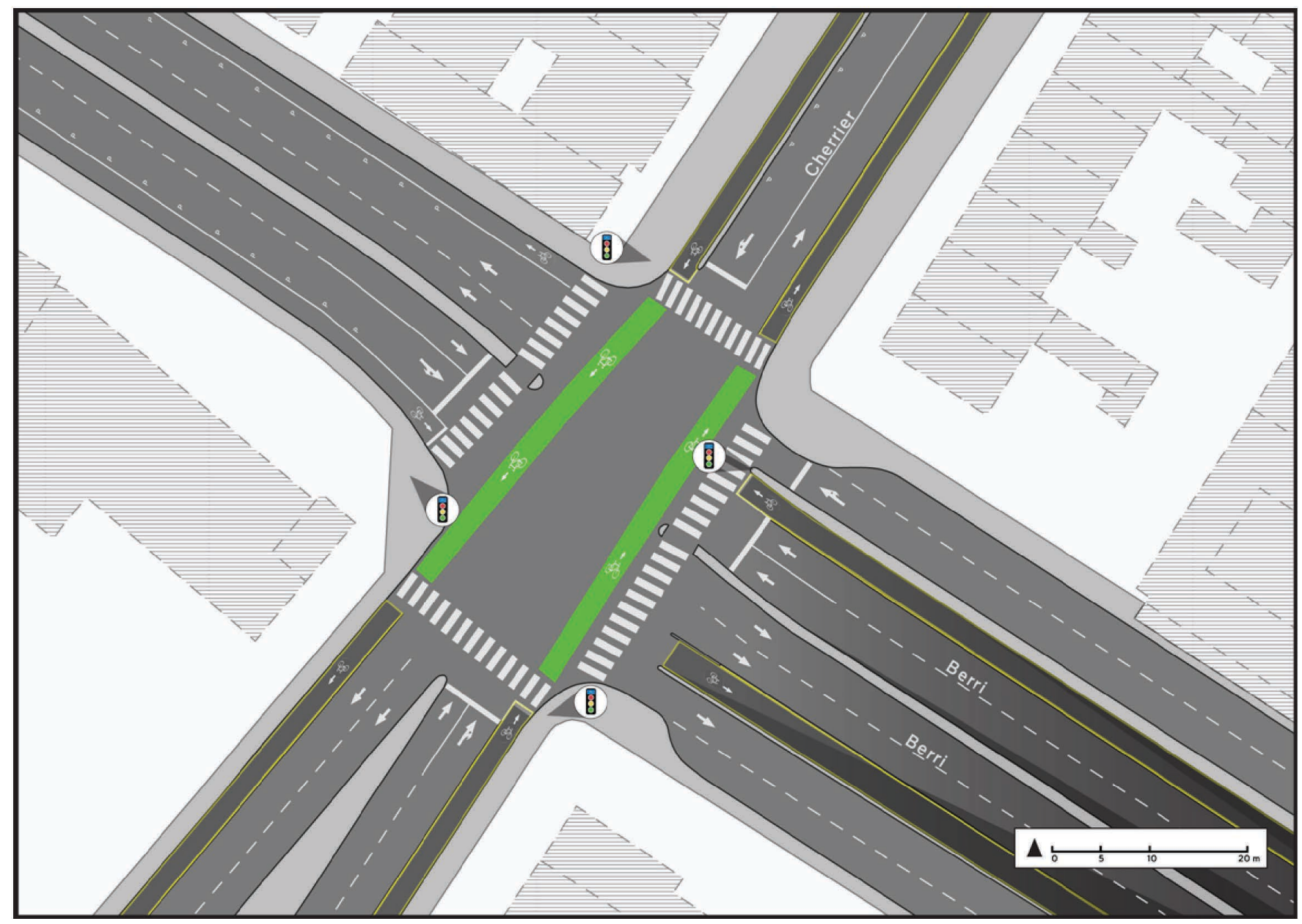

FIGURE 9 Design recommendations for Berri and Cherrier Streets.

of this intersection. As northbound users stay to the right side of the road, both straight-through northbound movement and right-hand eastbound turns are simplified, ensuring that all users follow the same directional logic. Any remaining potential danger of motor vehicles turning into straight-through bicycle traffic can be managed with bicycle signal phasing, giving each transport mode time differentials and permissions.

A number of design interventions and recommendations have been developed for the intersection of Saint Urbain Street and de Maisonneuve Boulevard (Figure 10).

\section{Choreographic Design for Saint Urbain and de Maisonneuve}

As the majority of observed conflict was concentrated around the bidirectional cycle track at this intersection, the primary design intervention here is to separate directional flows into a more choreographic arrangement of unidirectional cycle tracks. Eastbound users will continue to use the cycle track on de Maisonneuve Boulevard, but it has been converted to a solely eastbound cycle track, with its westbound counterpart located along the north edge of Ontario Street and President Kennedy Avenue. Unidirectional cycle tracks of adequate width rectify issues of bunching and two-way awkward maneuvers, allowing faster and slower users to interact safely. A bicycle signal installed on the now-contraflow eastbound cycle track should give a light phase to only eastbound bicycles, so that users have the option to safely continue straight ahead, or to make a smooth L movement to get to Ontario Street without any oncoming traffic.

\section{Prioritized Design for Saint Urbain and de Maisonneuve}

Here again, bold pavement markings identify which transport mode has priority in each direction. Clear and bold differentiation between bicycle and pedestrian crossing areas can help alleviate potential conflicts, as well as draw attention to vulnerable users when motorists are crossing their path. Some treatment, such as greenery or a curb, could also be installed between the eastbound bicycle track and the pedestrian sidewalk along the south edge of de Maisonneuve Boulevard, as several instances of pedestrians who were unaware of the bicycle track were observed. It is recommended that the southbound bicycle box be extended in width to allow confident leftturning riders to position themselves to the far left side in front of motorists. Here, also, a bicycle signal will give advanced priority of $5 \mathrm{~s}$ to southbound users to alleviate potential conflicts with right-turning motorists. 


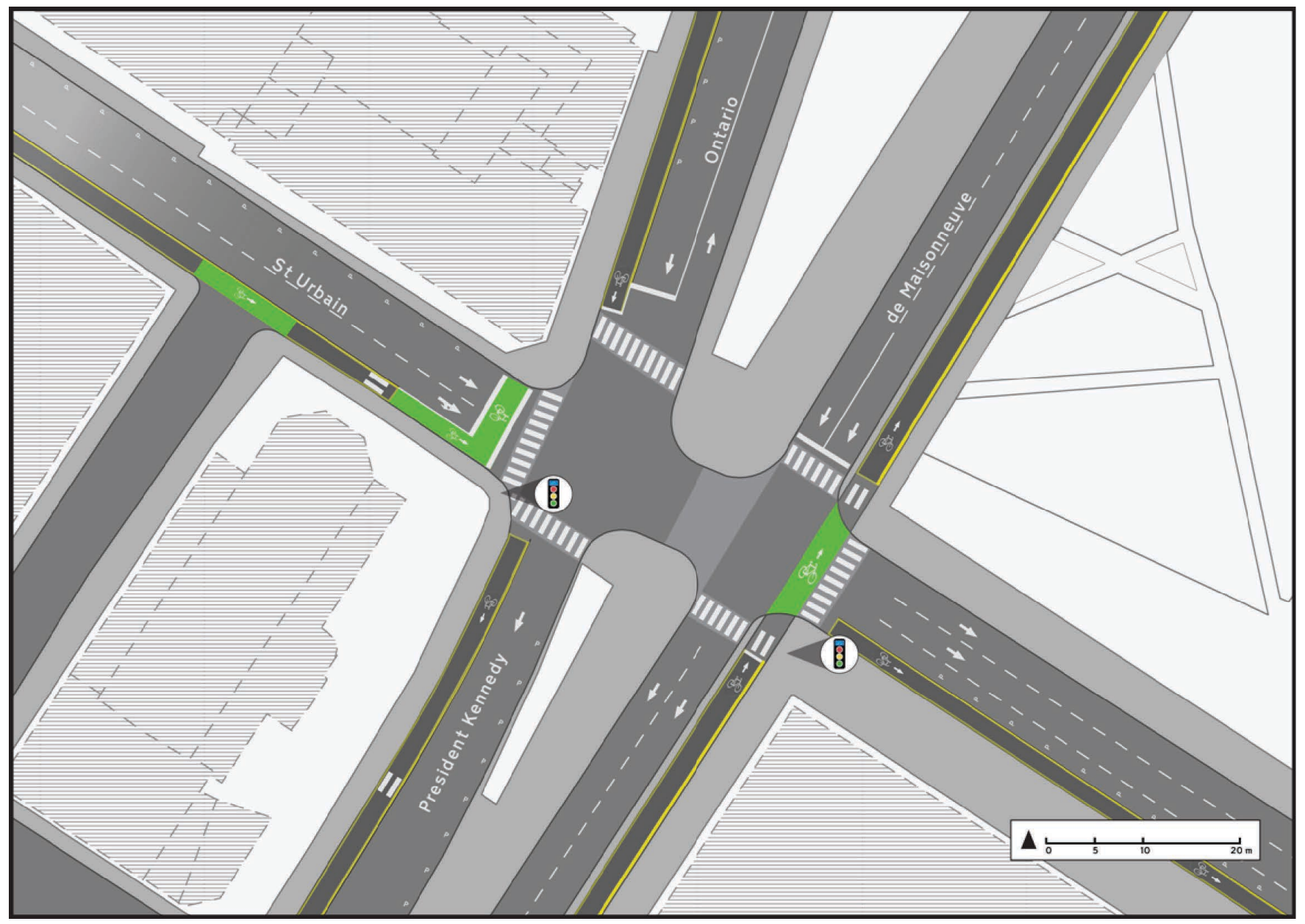

FIGURE 10 Design recommendations for Saint Urbain Street and de Maisonneuve Boulevard.

\section{Predictable Design for Saint Urbain and de Maisonneuve}

These design interventions eliminate the possibility of observing Desire Lines A, C, D, and N, which all contributed to conflicts with bicycle users approaching from surprising directions. Southbound users turning right now have a dedicated bicycle track on President Kennedy Avenue, as do the other westbound users from Ontario Street and de Maisonneuve Boulevard. Additionally, a bicycle track has been added to the south side of Saint Urbain Street for continuity as users move southward in a straight-through movement. A uniform directional logic is employed for all transport modes, except for one contraflow movement along the south edge of eastbound de Maisonneuve Boulevard, which is controlled by a dedicated bicycle signal phase. In the course of analyzing this intersection, a small number of counterflow northbound bicycle users were observed on the south side of Saint Urbain Street, either in the street or on the sidewalk. As a means of addressing this, it is recommended that a protected northbound bicycle corridor be implemented on a nearby street to complement the southbound movement on Saint Urbain Street.

\section{CONCLUSION}

The purpose of this study was to better understand negative perceptions surrounding intersections in Montreal with protected bidirectional bicycle facilities. The interplay between intersections and user behavior is important to analyze as $58 \%$ of bicycle collisions in Montreal occur at an intersection (14). The Desire Lines Analysis tool was used to perform a fine-grained analysis of bicycle user behavior at two carefully selected intersections in the city. In both intersections, the predominant flows of bicycle movements followed the prescribed design of the infrastructure, but more than a quarter of the observed desire lines in both instances did not. An analysis of these questionably legal behaviors and the collection of observed bicycle conflicts led to the creation of a conflict typology and recommendations for design interventions to rectify these observed conflicts. This typology identified three major themes from the observed conflicts: counterflow interactions, priority confusion, and directional awareness. Recommendations were put forward for a design that is choreographic, prioritized, and predictable.

This study shows that a fine-grained observational analysis such as the desire lines analysis can be used to shed light on human behavior-inspired designs for bicycle infrastructure. This tool can serve as a useful complement to a citywide network analysis, informing elected officials, planners, and engineers where and how citizens are using bicycles in the city, where there is conflict, and how it might be improved. This study could be expanded by including a larger number of intersections with bidirectional facilities. It was limited to two intersections because of constraints of time and resources. It might also be interesting to compare observed movements with simulations or models that implement various design interventions in an effort to understand what designs aid in reducing conflict. This 
analysis may also serve as helpful for cities to investigate intersection redesigns before and after interventions, as well as short-term pilot projects. This study, along with the works of Gehl and Svarre (8), Jacobs (9), and Whyte (10), affirms that by actively observing the urban environment, assumptions can be challenged and better life-sized cities for all citizens can be built.

\section{ACKNOWLEDGMENTS}

The authors thank Mikael Colville-Andersen, Clotilde Imbert, and James Thoem of Copenhagenize Design Company for their methodology guidance and design support. The authors also thank Joshua Adams, Mark Werner, and Devon Willis for their aid in data collection and Zvi Leve for photographic support.

\section{REFERENCES}

1. Pucher, J., R. Buehler, and M. Seinen. Bicycling Renaissance in North America? An Update and Re-Appraisal of Cycling Trends and Policies. Transportation Research Part A: Policy and Practice, Vol. 45, No. 6, 2011, pp. 451-475. https://doi.org/10.1016/j.tra.2011.03.001.

2. Teschke, K., M.A. Harris, C.C. Reynolds, M. Winters, S. Babul, M. Chipman, M. D. Cusimano, J. R. Brubacher, G. Hunte, S. M. Friedman, M. Monro, H. Shen, L. Vernich, and P.A. Cripton. Route Infrastructure and the Risk of Injuries to Bicyclists: A Case-Crossover Study. American Journal of Public Health, Vol. 102, No. 12, 2012, pp. 2336-2343. https://doi.org/10.2105/AJPH.2012.300762.

3. Pucher, J., J. Dill, and S. Handy. Infrastructure, Programs, and Policies to Increase Bicycling: An International Review. Preventive Medicine, Vol. 50, Supplement, 2010, pp. S106-S125.

4. Jacobsen, P.L. Safety in Numbers: More Walkers and Bicyclists, Safer Walking and Bicycling. Injury Prevention, Vol. 9, No. 3, 2003, pp. 205-209. https://doi.org/10.1136/ip.9.3.205.

5. Hull, A., and C. O'Holleran. Bicycle Infrastructure: Can Good Design Encourage Cycling? Urban Planning and Transport Research, Vol. 2, No. 1, 2014, pp. 369-406. https://doi.org/10.1080/21650020.2014 .955210 .
6. Vélo Québec. L'État du Vélo à Montréal en 2015. Vélo Québec, Montreal, Quebec, Canada, 2015.

7. Ville de Montréal. Montréal Annonce une Nouvelle Piste Cyclable Unidirectionnelle en Site Propre Sur le Boulevard Rosemont [press release]. http://www.newswire.ca/fr/news-releases/montreal-annonce-une -nouvelle-piste-cyclable-unidirectionnelle-en-site-propre-sur-le -boulevard-rosemont-581794861.html. Accessed July 15, 2016.

8. Gehl, J., and B. Svarre. How to Study Public Life, 2nd ed. Island Press, Washington, D.C., 2013. https://doi.org/10.5822/978-1-61091-525-0.

9. Jacobs, J. Downtown Is for People. Fortune Magazine, 1958. http://fortune .com/2011/09/18/downtown-is-for-people-fortune-classic-1958. Accessed July 10, 2016.

10. Whyte, W. H. The Social Life of Small Urban Spaces. Project for Public Spaces, New York, 1980.

11. Copenhagen Traffic Department. Traffic in Copenhagen: Traffic Figures 2007-2011. City of Copenhagen, Denmark, 2012. http://kk.sites.itera.dk /apps/kk_pub2/pdf/1029_NbpXmZHnuz.pdf. Accessed July 15, 2016.

12. Technical and Environmental Administration. Copenhagen: City of Cyclists. City of Copenhagen, Denmark, 2015. http://www.cycling-embassy.dk /wp-content/uploads/2015/05/Copenhagens-Biycle-Account-2014.pdf. Accessed July 15, 2016.

13. Miranda-Moreno, L. F., and T. Nosal. Weather or Not to Cycle: Temporal Trends and Impact of Weather on Cycling in an Urban Environment. Transportation Research Record: Journal of the Transportation Research Board, No. 2247, 2011, pp. 42-52. https://doi.org/10.3141/2247-06.

14. Morency, P., and M. S. Cloutier. Distribution Géographique des Blessés de la Route Sur L'île de Montréal; Cartographie pour les 27 Arrondissements. Agence de la Santé et Des Services Sociaux de Montréal, Santé Publique Québec, 2005.

15. Colville-Andersen, M., K. Maddox, P. Madruga, and A. Suhr. The Bicycle Choreography of an Urban Intersection: Desire Lines and Behavior of Copenhagen Bicycle Users. Copenhagenize Design Company, Copenhagen, Denmark, 2012.

16. Axinte, L., J. Furlong, E. Kränzle, W. Otchere-Darko, L. Rosset, G. Torres, M. Waiengnier, and D. Willis. Choreography of a Copenhagen Corner: Desire Line Analysis, Sфtorvet \& Dronning Louises Bro. Copenhagenize Design Company, Copenhagen, Denmark, 2014.

17. Imbert, C., and M. te Brömmelstoet. The Desire Lines of Bicycle Users in Amsterdam. Copenhagenize Design Company, Copenhagen, Denmark, 2014.

The Standing Committee on Bicycle Transportation peer-reviewed this paper. 